\title{
APROXIMACION AL BRONCE ANTIGUO Y PLENO EN EL SURESTE DE LA CAMPIÑA CORDOBESA: LOS YACIMIENTOS DEL CERRO DEL CASTILLO DE AGUILAR Y DE ZOÑAR
}

\author{
María Dolores RUIZ LARA \\ Juan Francisco MURILLO REDONDO
}

\section{Resumen}

En este trabajo se presentan dos yacimientos arqueologicos que, con una ocupación del Bronce Pleno, documentan una etapa que hasta el momento se había mostrado poco clara en el contexto general de Andalucía occidental y, en especial, en la Cuenca Media del Guadalquivir. Definido en base a una serie de objetos cerámicos y métalicos, este horizonte cultural cobra una especial relevancia como punto de encuentro de influjos procedentes de dos de las principales áreas culturales de la Edad del Bronce peninsular.

\section{Summary}

This paper analyses the Middle Bronze Age in the Middle Valley of Guadalquivir river by means of two archaelogical settlements in the province of Cordoba. They offer a distinctive material culture -pottery, metalwork- and also an increasing influence from two of the most important cultural areas of Iberia.

Hasta hace algunos años el lapso de tiempo comprendido entre los últimos momentos del Calcolítico y la formación del horizonte cultural tartésico, en el tránsito del II al I milenio, era prácticamente desconocido en Andalucía Occidental. El expediente solía resolverse con la pura y simple traslación de la cultura argárica al Medio y Bajo Guadalquivir (v.gr. BOSCH GIMPERA, 1954; LOPEZ PALOMO, 1979 y 1983) o con el recurso a una perduración del horizonte campaniforme de Carmona hasta casi el último cuarto del II milenio (HARRISON et alii, 1976). Sin embargo, tras la publicación de las secuencias estratigráficas de Mesa de Setefilla (AUBET, et alii, 1983) y de Monte 
Berrueco (ESCACENA-FRUTOS, 1985), la situación se ha modificado en profundidad, comenzando a definirse un Bronce antiguo y Pleno del Bajo Guadalquivir (RUIZ GALVEZ, 1984; SERNA et alii, 1984; CARO, 1989).

Con este artículo pretendemos aproximarnos a la problemática de esta etapa en la Cuenca Media del Guadalquivir a partir de los conjuntos de materiales procedentes de Prospecciones Arqueológicas Superficiales en dos yacimientos localizados en el término municipal de Aguilar de la Frontera. Estos constituyen, por el momento, el ejemplo más claro de un Horizonte Cultural de la Edad del Bronce diferenciado de los epígonos calcolíticos en la provincia de Córdoba, proporcionando unas pautas que, con la deseable realización de sondeos estratigráficos en los mismos, pueden ser de vital importancia para la interpretación arqueológica del II milenio a.C. en Andalucía Occidental.

Los dos yacimientos que presentamos se integran en el espacio geomorfológico denominado Campiña cordobesa, situada a caballo entre la inflexión de Sierra Morena y la Vega del Guadalquivir al Norte, y las Sierras Subbéticas al Sur. Se caracteriza por una topografía sencilla, con lomas de escasa altitud entre valles, y por tierras profundas y arcillosas que forman los clásicos bujeos en los que se asientan los cultivos cerealistas extensivos (LOPEZ ONTIVEROS, 1985; CEBAC, 1971).

El yacimiento de Zoñar ocupa una loma situada a la izquierda de la Carretera comarcal 329, de Aguilar a Puente Genil, dominando la Laguna de Zoñar y a poca distancia de la de El Rincón. El terrerno sobre el que se asienta está constituido por las margas terciarias características de la Campiña. La superficie está ocupada en la actualidad por un olivar; fueron precisamente las labores de plantación de nuevos olivos las que motivaron la exhumación de numerosos restos arqueológicos en una superficie de unos $3.000 \mathrm{~m}^{2}$.

Por su parte, el yacimiento de El Cerro del Castillo de Aguilar se ubica sobre un prominente cerro amesetado constituido por margas y areniscas, a cuyos pies se ha ido formando la localidad de Aguilar de la Frontera. Su proximidad al casco urbano, hasta quedar prácticamente integrado en él, ha propiciado su paulatina destrucción a lo largo de los siglos, iniciada con la construcción de las fortificaciones medievales y culminada en las últimas décadas con la instalación de los depósitos que abastecen de agua a la población. Los materiales arqueológicos aparecen dispersos por todo el cerro, con una especial concentración en las laderas N. y E. Las constantes remociones han ocasionado la desaparición de los niveles arqueológicos salvo en zonas muy localizadas.

La posición estratégica del asentamiento es incuestionable; junto a un vado del río de Cabra, jalona la importante ruta que ya desde la Prehistoria Reciente (MURILLO, 1991) unía el Valle Medio del Guadalquivir con el litoral malagueño a través de las Tierras de Antequera, con un trazado que con posterioridad seguirá la vía romana Corduba-Malaka. Junto a este eje principal N-S, confluye a los pies del Cerro del Castillo otro transversal que supone la vía de salida natural desde la Campiña del Guadajoz hacia el Genil Medio y la Campiña sevillana. 
Por otro lado, la disponibilidad de agua, cuyo abastecimiento estaba garantizado tanto por el ŕo como por un manantial localizado a los pies del Cerro, las fértiles tierras de cultivo situadas en su entorno y la localización de una salina en las proximidades, actuaron como factores de atracción para el poblamiento humano en este punto de la Campiña Occidental cordobesa, que, a diferencia de Zoñar, ofrece una dilatada secuencia ocupacional que abarca desde al menos el Calcolftico Final hasta nuestros días.

Para el estudio de los vestigios de la cultura material de ambos yacimientos hemos utilizado la totalidad de la muestra prospectada para el caso de Zoñar dado el probado carácter monofásico de su ocupación, en tanto que para el Cerro del Castillo de Aguilar nos hemos limitado a un pequeño lote de materiales encuadrables tipologicamente en la etapa que aquí nos interesa, eliminando el grupo de atípicos dado que la dilatada ocupación del asentamiento hace inoperante este tipo de material cuando procede de Prospecciones superficiales.

Los conjuntos de materiales de que disponemos están constituidos en su mayoría por fragmentos cerámicos. Así, en Zóñar la cerámica supone el $94,95 \%$, el sílex el 2,93\%, la piedra trabajada el $1,06 \%$, el adorno el $0,27 \%$ y el grupo de varios (pesas de telar) el $0,79 \%$.

Distinguimos dentro del conjunto cerámico fragmentos con decoración $(0,84 \%)$ y sin ella $(99,16 \%)$. Entre los primeros aparecen dos fragmentos de borde pertenencientes a vaso abiertos de gran tamaño, con impresiones (Fig. 3, $\mathrm{n}^{\circ}$ 141) e incisiones (Fig. 3, $\mathrm{n}^{\circ}$ 167) sobre el labio y un fragmento atípico de paredes muy gruesas y superficies toscas con impresiones de matriz de sección circular en la cara externa (Fig. 3, nº 206).

Por lo que respecta a la cerámica no decorada y a la morfología de los fragmentos, el mayor porcentaje corresponde a los bordes $(53,95 \%)$, seguido por los atípicos $(36,45 \%)$, las bases $(4,24 \%)$, los galbos $(2,82 \%)$, los arranques de cuello $(1,98 \%)$ y otros $(0,56 \%)$. Los bordes mejor representados son los salientes $(55,44 \%)$, en tanto que los entrantes $(26,44 \%)$, y rectos $(13,47 \%)$ son menos frecuentes, y los de orientación no determinable suponen el $4,15 \%$. La forma más común en la redondeada-apuntada $(39,90 \%)$, encontrándose a continuación la redondeada $(31,60 \%)$, semiplana $(20,21 \%)$, biselada $(4,66 \%)$ y plana $(3,63 \%)$.

En cuanto al acabado de las superficies, dominan las alisadas, tanto en el exterior como en el interior (39,83\% y $37,86 \%$ respectivamente), seguidas por las alisadas finas $(24,86 \%$ y $25,15 \%)$, alisadas toscas $(20,06 \%$ y $22,31 \%)$, toscas y erosionadas con un porcentaje similar $(4,52 \%$ y $4,80 \%)$, alisadas muy finas ( $4,52 \%$ en ambas superficies), espatuladas $(0,85 \%$ y $0,28 \%)$, bruñidas $(0,28 \%$ en las dos) y muy toscas $(0,56$ sólo en la superficie externa). 
El fuego de cocción más común es el oxidante $(36,73 \%)$, seguido por el altemo $(33,05 \%)$, reductor $(18,36 \%)$ y nervio de cocción $(11,86 \%)$. El desagrasante más frecuente es el de tamaño medio $(30,79 \%)$, y en menor medida el grueso $(20,90 \%)$, fino $(17,51 \%)$, muy fino $(15,25 \%)$, no apreciable $(9,33 \%)$ y muy grueso $(6,22 \%)$. Las cerámicas de Zoñar suelen presentar paredes muy gruesas $(44,06 \%)$ o gruesas $(41,81 \%)$, siendo menos abundantes las medias $(13,28 \%)$ y las finas $(0,85 \%)$.

La industria lítica se caracteriza por su pobreza, tanto a nivel cualitativo como cuantitativo. Sólo dos lascas retocadas (Fig. 2, A-1 y A-2), además de algunos restos de talla, componen el apartado de sílex, mientras la piedra trabajada está representada por varias molederas (Fig. 2, B-2) y un molino barquiforme.

En el grupo de varios hemos incluido tres fragmentos de pesas de telar de arcilla cocida. Presentan forma o bien de tendencia rectangular con una perforación (Fig. 2, F2) o dos (Fig. 2, F-3), o bien circular, en cuyo caso sólo se conserva una de las perforaciones (Fig. 2, F-1); éstas pueden ser cilíndricas o ligeramente troncocónicas. Por último, haremos referencia a un colgante elaborado sobre una concha de caracol, perforada en sentido longitudinal para facilitar su suspensión (Fig. 2, E-1).

Con respecto a la tipología cerámica, las formas más comunes son las derivadas de la esfera, sobresaliendo del conjunto los cuencos, con ejemplares de casquete esférico (Fig. $4, n^{\circ} 52,113,168,121$ y 148; Fig. 5, n 51 y 111) y semiesférico (Fig. 4, nº y 39). Los diámetros son en su mayoría de tipo medio (11-19 cm.), sólo superados en algunos casos (Fig. 5). En cuanto a la forma de los bordes, predominan los redondeados y redondeadoapuntados, en ocasiones con el labio vuelto (Fig. $5, \mathrm{n}^{\circ} 30$ ), y en menor medida biselados (Fig. 5, n 6; fig. 9, 159) y semiplanos (Fig. 5, n 19; Fig. 9, nº 60). Destaca un borde engrosado al exterior, con labio muy ancho y plano (Fig. 9, no 44). El acabado de las superficies suele ser alisado, si bien algunos ejemplares presentan alisados finos o incluso espatulados.

Los cuencos parabólicos constituyen una variedad a reseñar (Fig. 5, no 19; Fig. 6, $\mathrm{n}^{\circ}$ 43; Fig. $9, n^{\circ} 36,45,69,129$ y 170), pues sus diámetros, cuando se han podido determinar, superan los $25 \mathrm{~cm}$., correspondiendo por lo tanto a vasos de dimensiones muy grandes. con respecto a la forma de los bordes, predominan los biselados, aunque también están presentes los semiplanos, redondeados y redondeado-apuntados, mientras el acabado de las superficies sigue la tónica definida para los ejemplares ya descritos.

Incluidas en este mismo grupo se encuentran las formas de tendencia globular, con bordes muy entrantes y perfiles más o menos convexos (Fig. 6, $n^{\circ} 15$ y 3; Fig. 10, $n^{2} 46$, $33,38,61,143$ y 53 ), o bordes casi rectos (Fig. 6, $\mathrm{n}^{\circ} 1$ y 12 ; Fig. 10, $\mathrm{n}^{\circ} 63$ ). Los diámetros son grandes (19-25 cm.), sobrepasando en algunos casos estas dimensiones (Fig. 6, nº 3 y 12). Los bordes presentan por lo general forma redondeada o redondeada-apuntada, siendo menos frecuentes los semiplanos. En cuanto al acabado de las superficies, no difieren de las líneas marcadas con anterioridad, sin existir una notable diferencia entre la externa y la intema. Mención especial merece un vaso, que consideramos oportuno 
incluir en este conjunto a pesar de diferir sensiblemente de sus características generales. Presenta borde recto, cuello marcado, sobre todo al interior, y cuerpo globular (Fig. 7, $\mathrm{n}^{\circ}$ 14); las superficies están cuidadas y, atendiendo a su diámetro, hemos de incluirlo en el apartado de los de tamaño grande.

Otro grupo lo constituyen los vasos de perfil en $\mathrm{S}$, con el cuello más o menos marcado y borde muy exvasado (Fig. 7, n⿳2 5 y 58; Fig. 8, nº 48 y 53; Fig. 10, n² 54 y 16), o los de perfil más suave (Fig. 8, n 8, 11, 25 y 47; Fig. 9, n⿳⺈ 42 y 34). Los diámetros, en los casos que se han podido determinar, son grandes $(19-25 \mathrm{~cm}$.) o muy grandes (mayores de 25 $\mathrm{cm}$.). En cuanto a la forma de los bordes, predominan los redondeados, con escasa presencia de los otros tipos. Las superficies presentan por lo general un cuidado acabado, alisado o alisado fino, con menor presencia del alisado tosco.

Una forma difícil de encuadrar a efectos tipológicos es la nº 18 (Fig. 7) ya que presenta borde entrante, biselado, pero sin perfil sinuoso ni claramente globular, si bien en su mitad inferior parece que se insinúa una forma más cerrada que en la superior.

Por último, el grupo menos nutrido lo constituyen las formas carenadas, con la carena a media altura en todos los casos (Fig. 8, n²0; Fig. 10, n³1, 104, 163 y 165). El diámetro solo se ha podido determinar en un fragmento, que queda encuadrado en el apartado de recipientes de gran diámetro $(19-25 \mathrm{~cm}$.), mientras que las superficies oscilan entre las alisadas y alisadas toscas y las alisadas finas y bruñidas.

En cuanto a las bases, si bien buena parte de los grupos comentados deben tener, al menos en apariencia, base convexa, se han conservado varios fragmentos de bases más o menos planas (Fig. 10, n 95, 99 y 7), con la superficie de apoyo muy tosca o incluso con improntas de cestería (Fig. 3, $\mathrm{n}^{\circ} 112$ ).

Un último grupo lo representan varias fichas recortadas (Fig. 3, $n^{\circ} 204$ ). Presentan forma de tendencia circular, con los bordes bien perfilados y diámetro máximo en torno a $\operatorname{los} 6 \mathrm{~cm}$.

El conjunto de materiales procedentes del Castillo de Aguilar que presentamos está integrado en su totalidad por cerámicas no decoradas. En el tratamiento general de las superficies se aprecia un mayor cuidado de las exteriores frente a las interiores (Graf. 1), lo que contrasta con lo observado en Zoñar, donde ambas superficies recibían un trtamiento muy similar. El acabado más frecuente es el alisado fino ( $43 \%$ en superficie exterior y $27 \%$ en interior), muy equiparado con el alisado, en el cual se invierten los términos ( $21 \%$ en la superficie exterior y $40 \%$ en la interior), siendo más escasa la alisada muy fina ( $17 \%$ y $8 \%$ respectivamente), alisada tosca ( $1 \%$ y $17 \%)$, y bruñida ( $12 \%$ la externa), y apenas significativas la espatulada (6\% la externa), tosca y erosionada ( $2 \%$ y $4 \%$ en superficie interna).

En cuanto al fuego de cocción, el porcentaje más elevado corresponde al nervio de cocción (45\%), y en menor proporción al reductor (27\%), alterno $(17 \%)$ y oxidante (12\%). Los desgrasantes más utilizados son los de tipo medio (50\%), seguidos de los gruesos (26\%), finos (17\%) y muy gruesos (7\%). Con respecto al grosor de las paredes, 
las gruesas y medias se encuentran muy equiparadas (43\% y 40\%), resultando más bajo el f́ndice de las muy gruesas (17\%).

Atendiendo a la tipología cerámica, al igual que en Zónar, las formas mejor representadas son las derivadas de la esfera, destacando dentro del conjunto los cuencos, con una serie de variantes que pasamos a comentar. Contamos con algunos ejemplares semiesféricos, de borde entrante (Fig. 12, $\mathrm{n}^{\circ} 12$ ) o saliente (Fig. 12, $\mathrm{n}^{\circ} 10,11,13$ y 14), y forma redondeada o redondeada-apuntada; los diámetros de tipo medio $(11-19 \mathrm{~cm}$.), y las superficies alisadas $o$ alisadas finas.

Otra variante dentro de este grupo la constituyen los cuencos carenados (Fig. 12, $\mathrm{n}^{2}$ 9), de menor altura que los precedentes y diámetro medio. Destacan los de diámetro muy grande (entre 20 y $32 \mathrm{~cm}$.) con perfil convexo (Fig. 11, $\mathrm{n}^{\circ} 1$ y 2 ; Fig. 12, $\mathrm{n}^{\circ} 8$ ) o carenado (Fig. 11, n⿳2 3, 4, y 5; Fig. 12, $n^{2} 6$ y 7), por lo general con la línea de carenación a media altura, si bien en una ocasión va inmediatamente debajo del borde (Fig. 11, n 5). La dirección de los bordes es siempre entrante y su forma redondeada o redondeada apuntada. Con respecto al acabado de las superficies predominan las brunidas, alisadas muy finas y alisadas finas.

Las formas de tendencia globular y borde entrante, muy abundantes en Zớar, son más escasas en el Castillo de Aguilar (Fig. 13, $\mathrm{n}^{\circ} 15$ y 16). Se trata de vasos de grandes dimensiones, pues sus diámetros oscilan entre 22 y $29 \mathrm{~cm}$. Los bordes son redondeadoapuntados y en el acabado de la superficie contrasta la extema, más cuidada, con la interna. Una variante dentro de este grupo la constituyen los ejemplares con borde exvasado (Fig. 12, $\mathrm{n}^{2} 17,18$ y 19), de grandes dimensiones (sus diámetros oscilan entre 29 y $43 \mathrm{~cm}$.), y superficie externa tratada con cuidado.

Por último, contamos con algunas formas de carena a media altura, con bordes exvasados (Fig. 13, $\mathrm{n}^{\circ} 23$ ) o rectos (Fig. 12, n⿳202). En algunos casos solo se conservan fragmentos del galbo (Fig. 12, no 21 y 22), por lo que resulta imposible determinar el perfil. En cuanto a las dimensiones, contamos con un ejemplar cuyo diámetro supera los $25 \mathrm{~cm}$. (Fig. 13, $\mathrm{n}^{\circ} 23$ ), siendo los restantes más pequeños (Fig. 12, no 20: $19 \mathrm{~cm}$.; $\mathrm{n}^{\circ} 21$ : $21 \mathrm{~cm}$. en la línea de carena). El acabado de las superficies se mantiene en la misma linea señalada para los grupos descritos más arriba, si bien con un contraste menos acusado entre ambas superficies, alisadas finas y muy finas las extemas y alisadas las internas.

A este conjunto de materiales cerámicos procedentes del Cerro del Castillo de Aguilar debemos añadir una alabarda y un hacha plana halladas en circunstancias desconocidas y conservadas en el Museo Arqueológico Nacional, donde ingresaron por donación de Sandars. Ambas fueron objeto de una breve reseña firmada por MELIDA (1920). Con posterioridad, el hacha fue publicada por CARRIAZO (1947: 783, Fig. 604) e incluida en el corpus de MONTEAGUADO (1977: 47, Lám. 11, 207), pero la alabarda, salvo algunas referencias ocasionales (CARRIAZO, 1947: 783; BLANCE, 1971: 194), ha permanecido virtualmente olvidada. En su síntesis sobre estas armas, SCHÜBART hace 
alusión a esta pieza, señalando la posibilidad de que hubiera podido estar enmangada como puñal (SCHÜBART, 1973: nota 16).

La alabarda presenta un aspecto macizo, con un fuerte nervio que recorre la hoja y tres remaches (no conservados) que asegurarían la fijación al mango. sus dimensiones son $200 \mathrm{~mm}$. de longitud y $94 \mathrm{~mm}$. de anchura máxima. La inclusión de esta pieza en uno de los tres tipos definidos por SCHÜBART (1973) plantea ciertos problemas, si bien la mayor parte de los rasgos lleva a su asimilación al grupo de alabardas argáricas. La aplicación del índice IP (anchura/longitud) de LULL (1983) reafirma esta vinculación, con un valor de 0,47, muy próximo al de las alabardas de las sepulturas 534 y $994 \mathrm{de} \mathrm{El}$ Argar, y 62 de El Oficio, todas ellas anchas y cortas. Continuando con los criterios morfométricos usados por LULL, obtenemos un índice de concavidad (IC) de 0,20, propio del grupo de alabardas con una mínima concavidad. Por último la relación IP/IC se aproxima al tipo IIIb (alabardas de Arrayanes y de las sepulturas 169 y 533 de El Argar), si bien su IP, propio de un arma algo más esbelta, supera ligeramente el 0,44 propuesto por LULL. Por lo que respecta a la forma de la base (en arco), ésta no coincide con la angular doble que presentan los tres ejemplares de este subtipo. Sí existe plena coincidencia en el número de remaches.

Por lo que respecta al hacha, se trata de un ejemplar de $194 \mathrm{~mm}$. de longitud, 94 de anchura y 13 de grosor (MONTEAGUADO, 1977), de forma trapezoidal y de filo no desarrollado. BLANCE (1971:173) la incluye dentro de las hachas tipo Tajo, y MONTEAGUDO(1977: 47) en su tipo 2C. Hemos aplicado a nuestro ejemplar los criterios de clasificación morfométrica usados por LULL (1983b) para las hachas argáricas. Los resultados obtenidos para los distintos índices son los siguientes:

Indice de divergencia de los lados: 0,26

Indice de exvasamiento: 0,43

area de la superficie del hacha: $130,27 \mathrm{~cm}^{2}$

Indice de rentabilidad: 0,71

a partir de estos índices, podemos incluir el hacha procedente del Castillo de Aguilar dentro del Tipo I distinguido por LULL (índice de divergencia $<0,35$ ), y dentro de éste en el subtipo MG (área superior a $68 \mathrm{~cm}^{2}$ ). Debemos reseñar el hecho de que el área del hacha de Aguilar sea casi $40 \mathrm{~cm}^{2}$ superior a la máxima considerada por LULL para las hachas argáricas. Por último, la aplicación del índice de rentabilidad sitúa a la pieza que estamos estudiando dentro del grupo de menor rentabilidad en la relación filo/masa de metal invertida.

Una vez vistos los conjuntos materiales de ambos yacimientos, pasamos a encuadrarlos dentro de su contexto cronológico-cultural. Para tal fin tropezamos con la dificultad impuesta por la poca tipicidad de las formas cerámicas, en especial por lo que a Zoñar 
respecta. Sin embargo, las muestras analizadas tienen la suficiente significación estadística como para que podamos considerar indicativa tanto la presencia como la ausencia de una forma o tipo determinado, asi como las asociaciones de los mismos. El carácter monofásico de Zoñar, con ausencia de ocupación calcolitica previa y del Bronce Final Tartésico posterior supone un elemento de gran importancia a la hora de fijar su ubicación cronológico-cultural, en tanto que los materiales que presentamos del Cerro del Castillo de Aguilar deben considerarse inmersos en una larga e ininterrumpida ocupación que abarcarfa desde el Calcolítico Pleno-Final (con platos de borde engrosado y campaniforme inciso) hasta la actualidad.

En este último yacimiento las formas cerámicas que hemos seleccionado consisten en cuencos hemiesféricos y de cuarto de esfera, vasos parabólicos, globulares cerrados, de perfil en S y con carena a media altura. Por lo que respecta al Cerro del Castillo de Aguilar, junto a vasos hemiesféricos, globulares cerrados y de perfil en $\mathrm{S}$, contamos con cuencos carenados de gran diámetro, con borde entrante y carena situada inmediatamente bajo éste, y con vasos de carena media y borde exvasado.

Los cuencos hemiesféricos y de cuarto de esfera son formas poco definitorias ya presentes en los conjuntos cerámicos neolíticos y más frecuentes en los calcolíticos. En el Monte Berrueco de Medina Sidonia (ESCACENA-FRUTOS, 1985) los encontramos desde el Estrato I, que supone la transición entre el Calcolítico Final y el Bronce Pleno, hasta el V, del Bronce Final Precolonial, momento en el que se hacen más escasos para terminar por desaparecer. En el Sureste constituyen una de las formas más comunes dentro de los yacimientos argáricos (ARRIBAS et alii, 1974; MOLINA-PAREJA, 1975), formando parte tanto de los ajuares funerarios como domésticos (LULL, 1983: 70). Es significativa la ausencia en Zónar de los característicos vaso hemiesféricos ligeramente achatados y con el borde entrante, presentes en el Bronce Antiguo y Pleno de Monte Berrueco (ESCACENA-FRUTOS, 1985: v. gr. Fig. 12, 35; 13, 44; 17, 87; 19, 108), en los niveles del Bronce Pleno de Mesa de Setefilla (AUBET et alii, 1983: Fig. 15, 5-9; 18, 25-29) y en los enterramientos en cista de la provincia de Huelva, donde aparece en Becerrero y en Beas (AMO, 1975: Láms. 98, 3; 101, 1 y 2; 105, 2; 107, 1; 109, 4; 121). Esta forma, documentada en el Cerro del Castillo y en varios asentamientos más de la Cuenca Media del Guadalquivir (MURILLO, 1991), está también presente entre los materiales de las Unidades Estratigraficas del Bronce Pleno del Corte 1 de las excavaciones realizadas durante los meses de Abril y Mayo de 1992 en el yacimiento de Colina de los Quemados, en Córdoba (MURILLO, 1992 e.p.).

Lo mismo cabe decir en relación con los vasos globulares de borde entrante y con los de perfil en S, presentes ya en contextos calcolíticos. En Monte Berrueco encontramos vasos globulares cerrados desde el Estrato I (ESCACENA-FRUTOS, 1985: Fig. 10, 15); aumenta su representación en los Estratos II (Fig. 13, 51; 14, 55; 15, 75-77) y III (Fig. 18, 102 y $105 ; 21,120 ; 23,147$ y 148), del Bronce Antiguo y Pleno, y perduran en los Estratos IV a VII, del Bronce Final (v. gr. Fig. 25, 163; 28, 194-196; 32, 249-252; 33, 261), 
advirtiéndose en estos últimos momentos cierta tendencia a sustituir los bordes redondeados y apuntados por otros semiplanos o con un ligero engrosamiento al interior. También en la Fase I de Mesa de Setefilla hallamos vasos de este tipo (AUBET et alii, 1983: Fig. 20), en algún caso con borde biselado muy similar al ejemplar nº 18 de Zoñar. Con todo, en este yacimiento sevillano los vasos globulares cerrados son poco frecuentes. Con mayor abundancia se presentan en cambio en la Colina de los Quemados, donde son la forma más representativa del Estrato 18 (LUZON-RUIZ MATA, 1973), fechable en la segunda mitad del II milenio (PELLICER, 1978) y de la Unidad Estratigráfica 109 de la Fase II del Corte 1, excavado en 1992 (MURILLO, 1992, e.p.).

En cuanto a los vasos de perfil en S, aparecen en los mismos ambientes culturales que venimos analizando, aunque en una proporción muy inferior a la que muestran en Zoñar. Así, en Monte Berrueco están presentes en el Estrato III (ESCACENA-FRUTOS, 1985: Fig. 17, 95; 21, 119). En el Cerro del Castillo de Aguilar tenemos vasos globulares con gollete cilíndrico (Fig. 12, 17-19) similares a otros procedentes de Mesa de Setefilla, entre ellos uno integrante del ajuar de la sepultura del Estrato XIV (AUBET et alii, 1983: Figs. 19, 30; 21, 37). Estos vasos șon también característicos de los ajuares de las cistas onubenses (AMO, 1975: Láms. 113; 114, 2; 118, 2; 122).

Más definitorio resulta el cuenco parabólico de Zónar ( $\left.n^{\circ} 19\right)$, forma no presente en los yacimientos de Andalucía Occidental que venimos considerando y cuyos paralelos deben buscarse en los conjuntos cerámicos argáricos, donde es relativamente frecuente. Así, la encontramos en los estratos I y II de Cuesta del Negro (MOLINA-PAREJA, 1975: Figs. 16, 2; 21, 32; 36) y en el Estrato VIII del Cerro de la Encina (ARRIBAS et alii, 1974: Fig. 23, 357), encuadrables en un momento temprano de la Fase B de El Argar.

Al mismo ambiente cultural apuntan los paralelos para los vasos de gran diámetro, borde entrante y carena elevada, más o menos acusada, del Cerro del Castillo de Aguilar. Estos recipientes están bien representados en el Monte Berrueco, donde son característicos del Estrato III, del Bronce Medio (ESCACENA-FRUTOS, 1985: Figs. 19, 20 y 22), y se les considera extensión occidental de los vaso argáricos de las formas 2, 3 bis y 6 de SIRET, que suelen presentar un perfil más suave y sin carena marcada, y una tendencia a fondos cónicos, como podemos apreciar en ejemplares de Cuesta del Negro (MOLINAPAREJA, 1975: v. gr. Figs. 40, 163; 45, 191-192) o del Cerro de la Encina (ARRIBAS et alii, 1974: v. gr. Figs. 19, 343; 54, 166).

Un último conjunto de vasos presentes en los yacimientos aguilarenses que venimos estudiando está integrado por los carenado. Para el n² 23 del Cerro del Castillo contamos con un paralelo casi exacto en un vaso del Estrato II de Monte Berrueco (ESCACENAFRUTOS, 1985: Fig. 13,47). Por lo que respecta al recipiente de carena media de Zoñar ( ${ }^{\circ} 20$ ), hallamos modelos en otros de la Fase I de Mesa de Setefilla (AUBET et alii, 1983: Fig. 18, 18), así como entre los ajuares de las cistas de Huelva (AMO, 1975: Láms. 100, $3 ; 109,1 ; 121)$. Estos vasos carenados guardan también cierta relación con algunos de los incluidos por SCHÜBART $(1971 ; 1974)$ bajo la denominación de cuencos tipo Atalaia. 
En las páginas precedentes hemos presentado los conjuntos de materiales hallados a partir de prospecciones superficiales en los yacimientos de Cerro del Castillo de Aguilar y de Zoñar, ambos en el término municipal de Aguilar de la Frontera. El estudio de estos materiales cerámicos nos ha llevado a plantear una serie de relaciones con yacimientos como Mesa de Setefilla y Monte Berrueco en el Bajo Guadalquivir, con el horizonte de las cistas onubenses y con los yacimientos argáricos granadinos de Cuesta del Negro y Cerro de la Encina.

Resumiendo lo arriba expuesto, debemos señalar la atipicidad de la mayor parte de las formas cerámicas de Z6ñar, de gran tamaño y de perfiles derivados de la esfera, simples o en S. En comparación, el Cerro del Castillo muestra una mayor calidad general en los tratamientos, así como una mayor significación tipológica de su repertorio formal, para cuya práctica totalidad hallamos paralelos en los Estratos II y III de Monte Berrueco y en la Fase I de Mesa de Setefilla.

Por lo que a la hoja de alabarda y al hacha plana del Cerro del Castillo se refiere, su análisis nos introduce en un circuito de relaciones que conectan el Guadalquivir Medio con los principales focos metalúrgicos del Mediodía Peninsular. La inclusión de la alabarda de Aguilar en el Tipo III-b de LULL (1983), nos la situaría en un momento temprano dentro de la secuencia evolutivo-cronológica propuesta por este autor (1983: 201), todo ello siempre y cuando, como hemos deducido a partir de la aplicación de los distintos índices, nuestra alabarda se incluya dentro de la serie de alabardas argáricas.

La interpretación de esta pieza en un punto tan alejado de los núcleos de desarrollo argárico resulta difícil en el estado actual de la investigación. Su consideración como producto de comercio llegado desde un foco argárico del Sureste, aunque factible, presenta a nuestro juicio el inconveniente de admitir su difusión en un momento en el que en el propio foco argárico se está formando el tipo. Por otro lado, cabría considerar la problemática planteada por las alabardas no argáricas tipo Montejícar y Carrapatas (SCHÜBART, 1973) en función de las interrelaciones entre las diversas áreas geográfico-culturales en que se inscriben, así como la necesaria revisión cronológica a partir del camino abierto por LULL (1983) y de las recientes propuestas para los ejemplares jienneses de Peñalosa y Cerro Benzalá (CARRASCO-PACHON, 1986).

Las peculiaridades reconocidas para la alabarda de Setefilla (AUBET-SERNA, 1981), unidas a las que ya observamos al estudiar la que aquí nos ocupa, podrían llevar en un futuro a plantear la posible existencia de un foco metalúrgico en el Medio y Bajo Guadalquivir, independiente pero a la vez interconectado con los restantes ya definidos en la Península (cfr. MURILLO, 1990). En este ámbito tendrían cabida no sólo las citadas alabardas de Setefilla y Aguilar, sino también otras perdidas o mal documentadas como las de Guadalcanal (SIRET, 1887) o Córdoba (BLANCE 1971), y las de Ecija (SCHÜ- 
BART, 1973) y El Laderón (BERNIER et alii, 1983), que marcan la apertura a relaciones culturales distintas a las argáricas.

La valoración del hacha resulta aún más problemática dada su no necesaria vinculación con el mundo argárico y su mayor amplitud cronológica. Así, pordráamos relacionarla con otros contextos remontables a momentos avanzados y finales del Calcolítico. Esto conlleva que el análisis morfométrico que hemos realizado a partir de los criterios de LULL (1983b) sea sólo indicativo, teniendo el único valor de mostramos su carácter arcaico y poco rentable en la relación filo/metal invertido, al menos por lo que a la dinámica de las hachas argáricas se refiere.

La casi segura pertenencia de ambas piezas a un ajuar funerario parece apuntar a la coincidencia entre lugar de hábitat y lugar de enterramiento, en consonancia con lo que conocemos para estos momentos a partir de Monte Berrueco (ESCACENA-FRUTOS, 1982) de Mesa de Setefilla (AUBET-SERNA, 1981) o de la aún inédita sepultura excavada por LOPEZ PALOMO (1990) en el Castillo de Monturque.

En síntesis, parece claro el encuadre del Cerro del Castillo en un momento que, a juzgar por ciertas formas cerámicas, como los vasos globulares cerrados, los grandes cuencos de carena alta y borde entrante y el vaso de carena media y borde exvasado, y por las armas metálicas, podría situarse en un momento paralelo al Bronce Antiguo del Estrato II de Monte Berrueco, fechado por C-14 en $1670 \pm 80$ (ESCACENA-FRUTOS, 1985). La ocupación continuaría durante el Bronce Pleno, caracterizada por los típicos cuencos achatados de borde entrante presentes en la Fase I de Mesa de Setefilla, definitoria del Bronce Pleno y datada en $1570 \pm 95$ (AUBET et alii, 1983). Este mismo horizonte se fecha en Monte Berrueco en el $1360 \pm 80$ a.C. (ESCACENA-FRUTOS, 1985).

Por lo que respecta a Zбñar, la atipicidad de sus formas cerámicas impide precisar su posición cronológica, aunque debemos valorar la presencia de los vasos globulares cerrados, de los de perfil en S, del vaso carenado y del gran vaso parabólico. Los primeros están bien representados en los estratos II y III de Monte Berrueco (ESCACENAFRUTOS, 1985), del Bronce Antiguo y Pleno. Para el vaso carenado ya señalamos paralelos tanto en los ajuares de las cistas de Huelva (AMO, 1975), como en la Fase I de Mesa de Setefilla (AUBET et alii, 1983); los vasos parabolicos los encontramos en Monte Berrueco (ESCACENA-FRUTOS, 1985) y en los poblados argáricos de Cuesta del Negro (MOLINA-PAREJA, 1975) y Cerro de la Encina (ARRIBAS et alii, 1974). Esto, unido al argumento de silencio que supone la ausencia de otras formas cerámicas documentadas en Cerro del Castillo, nos lleva a proponer una cronología del Bronce Pleno para Zônar, pudiendo deberse sus peculiaridades a la propia orientación económica y a la entidad del asentamiento, a todas luces inferior a la de otros yacimientos como el cercano Cerro del Castillo o Mesa de Setefilla. 


\section{Bibliografia}

AMO, M. (1975); "Enterramientos en cista de la provincia de Huelva", Huelva Prehistoria y Antigüedad, Madrid.

ARRIBAS, A. et alii, (1974); "Excavaciones en el poblado de la Edad del Bronce Cerro de la Encina, Monachil (Granada). El corte estratigráfico nº 3"', E.A.E., 81, Madrid.

AUBET, M.E. et alii, (1983); “'La Mesa de Setefilla. Lora del Río(Sevilla). Campaña de 1979", E.A.E., 122, Madrid.

AUBET, M.E. et SERNA, M.R. (1981); “'Una sepultura de la Edad del Bronce en Setefilla", T.P., 38, pp. 225-251.

BERNIER, J. et alii (1983); Nuevos yacimientos arqueológicos de Córdoba y Jaén, Córdoba.

BLANCE, B. (1971); "Die Anfange der Metallurgie auf der Iberischen Halbinsel", S.A.M., 4, Berlín.

BOSCH GIMPERA, P. (1954); "La Edad del Bronce de la Península Ibérica", A.E.Arq., XXVII, pp. 49-92.

CARO, A. (1989): "Consideraciones sobre el Bronce Antiguo y Pleno en el Bajo Guadalquivir", Tartessos. Arqueología Protohistórica del Bajo Guadalquivir, 1989, pp. 85-120.

CARRASCO, J. et PACHON, J.A. (1986); " La Edad del Bronce en la provincia de Jaén", Homenaje a Siret, pp. 361-377.

CARRIAZO, J. (1947); "La Edad del Bronce”, H.E.M.P., tomo I.1, Madrid, pp. 755-851.

CEBAC (1971); Estudio agrobiológico de la provincia de Córdoba, Madrid.

ESCACENA, J.L. et FRUTOS, G. (1982); “'Enterramientos de la Edad del Bronce del Cerro del Berrueco (Medina Sidonia, Cádiz)”, Pyrenae, 17-18, pp. 165-189.

ESCACENA, J.L. et FRUTOS, G. (1985); “"Estratigrafía de la Edad del Bronce en el Monte Berrueco (Medina Sidonia, Cádiz)”, N.A.H., 24, pp. 7-90.

HARRISON, R.J. et alii, (1976); "The Bell Beaker Pottery from El Acebuchal, Carmona (Sevilla)", M.M., 17, pp. 74-141.

LOPEZ ONTIVEROS, A. (1985); "Relieve y Morfología", Córdoba y su provincia, vol. I, pp. 23 ss., Sevilla.

LOPEZ PALOMO, L.A. (1979); La cultura ibérica del Valle Medio del Genil, Córdoba.

LOPEZ PALOMO, L.A. (1983); “'De la Edad del Bronce al mundo ibérico en la Campiña del Genil", Actas I Congreso Historia de Andalucia, vol. 1, pp. 67-127.

LOPEZ PALOMO, L.A. (1990); "Prospección arqueológica con sondeo estratigráfico en el yacimiento de Colina del Castillo de Monturque, en el término municipal de Monturque, Provincia de Córdoba", A.A.A. 87, 11, pp. 180-192. 
LULL, V. (1983); "Contribución al estudio tipológico de las alabardas argáricas", XVI C.N.A., PP. 189-205.

LULL, V. (1983b); La cultura de El Argar, Madrid.

LUZON, J.M. et RUIZ MATA, D. (1973); Las raíces de Córdoba. Estratigrafia de la Colina de los Quemados, Córdoba.

MELIDA, J.R. (1920); “Adquisiciones del museo Arqueológico Nacional de Madrid", R.A.B.M., XLI, pp. 481-528.

MOLINA, F. et PAREJA, E. (1975); “'Excavaciones en la Cuesta del Negro (Purullena, Granada)"', E.A.E., 86, Madrid.

MONTEAGUDO, L. (1977); "'Die Beile auf der Iberischen Halbinsel”, Prahistorische Bronzefunde, 6, Munich.

MURILLO, J.F. (1990); “'Estado de la cuestión sobre el poblamiento durante el Calcolítico y la Edad del Bronce en las Subbéticas Cordobesas", AAC, 1, pp. 53-80.

MURILLO, J.F. (1991); Estudio del poblamiento durante el Bronce Final y el Orientalizante en la Cuenca Media del Guadalquivir, Tesis Doctoral, Univ. de Córdoba. PELLICER, M. (1978); "Problemática general de los inicios de la iberización en Andalucía Occidental”, Ampurias, 38-40, pp. 3-23.

RUIZ GALVEZ, M. (1984); "Reflexiones terminológicas en tomo a la Edad del Bronce Peninsular', T.P., 41, pp. 323-342.

SCHÜBART, H. (1972); “AAcerca de la cerámica del Bronce Tardío en el Sur y Suroeste peninsular”, T.P., 29, pp. 153-182.

SCHÜBART, H. (1973); "Las alabardas tipo Montejícar" , Estudios dedicados al Dr. Pericot, pp. 247-269.

SCHÜBART, H. (1974); "'La cultura del Bronce en el Sudoeste peninsular. Distribución y definición”, Miscelánea Arqueológica, XXV Aniversario de los Cursos de Ampurias, pp. 345-370.

SERNA, M.R. et alii (1984); " Nuevos datos para una definición del Bronce Antiguo y Pleno en el Bajo Guadalquivir", The Deya Conference of Prehistory, B.A.R., 229, vol. III, pp. 1051-1083.

SIRET, H. (1887); Les Ages Préhistoriques en Espagne, Bruselas. 


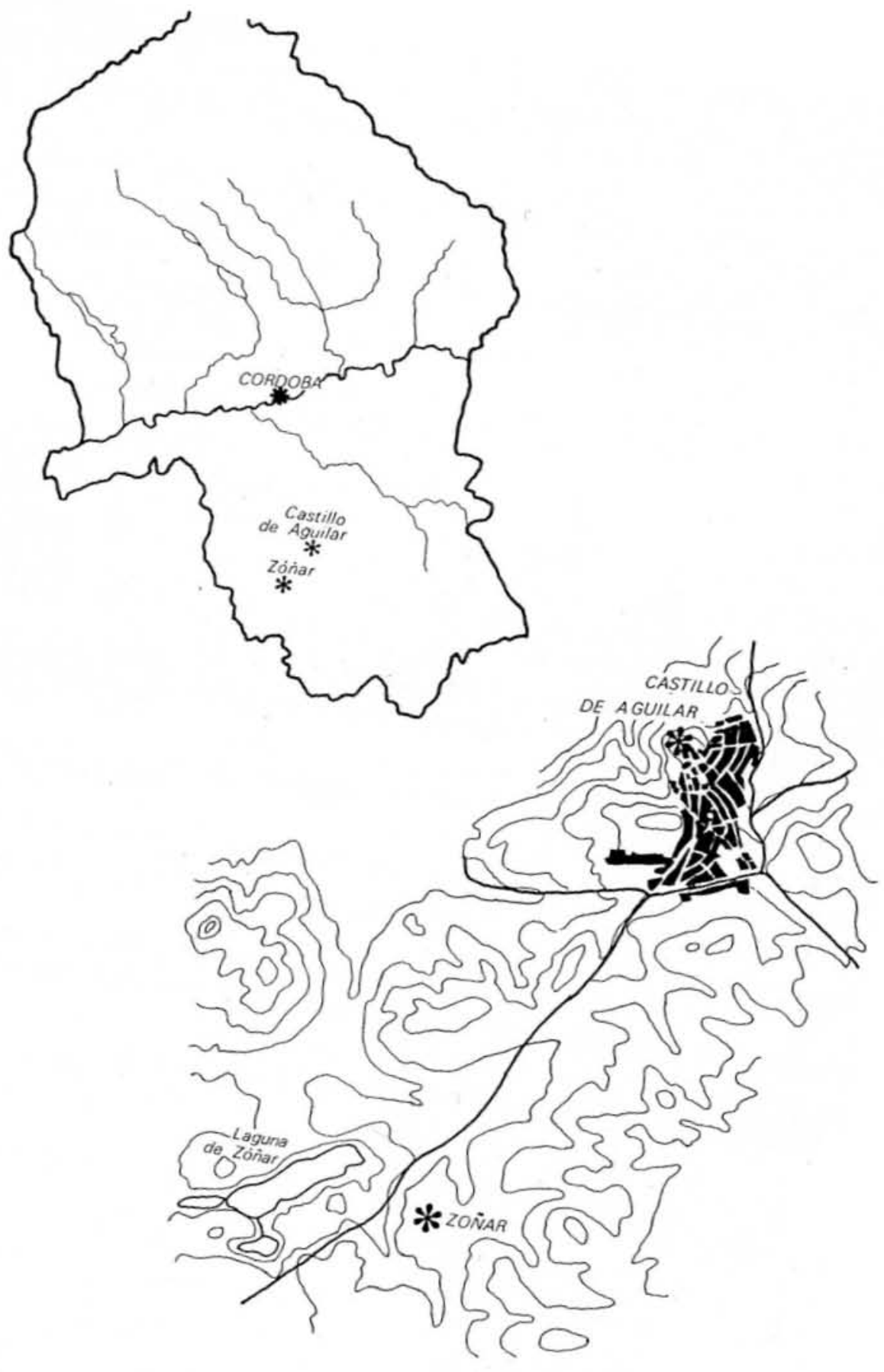

FIGURA 1 



FIGURA 2 

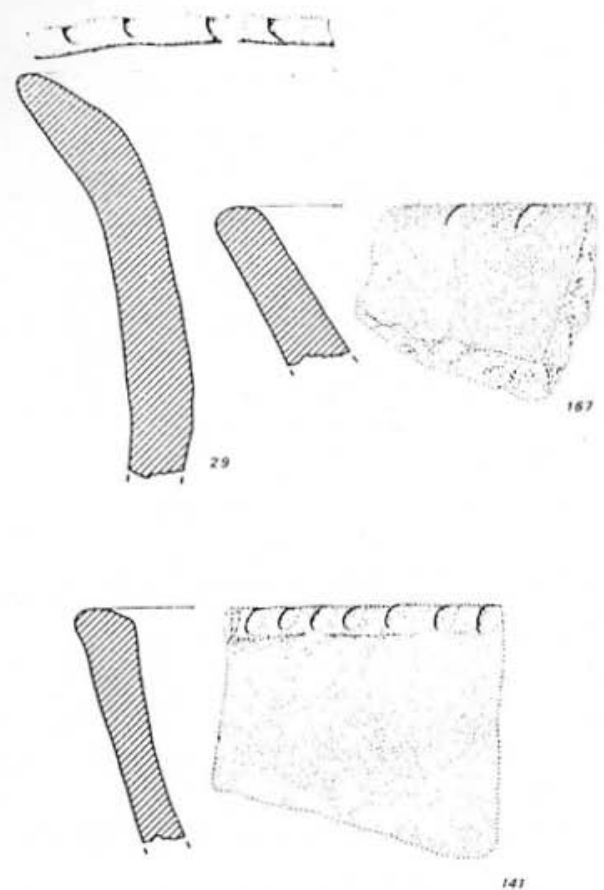

(4)
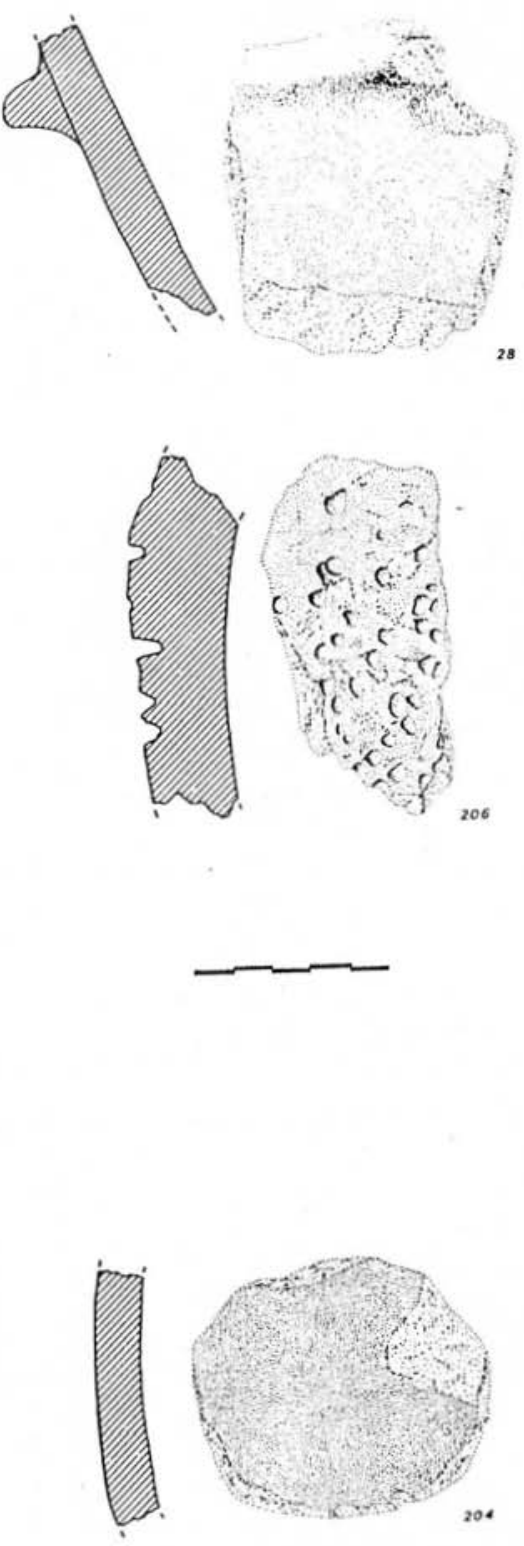

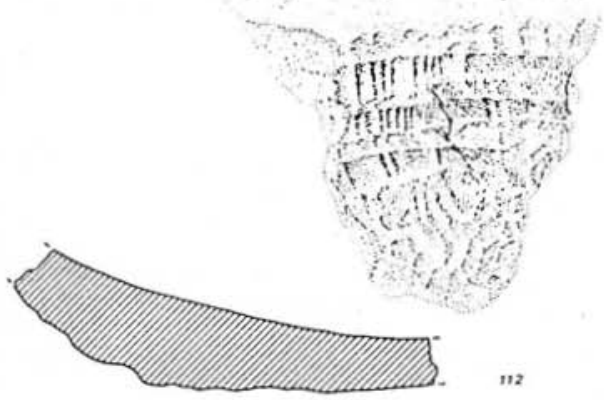

\section{FIGURA 3}

24 Grupo de investigación P.A.I. HUM 236 | http://www.arqueocordoba.com/publ/anales.htm --- 

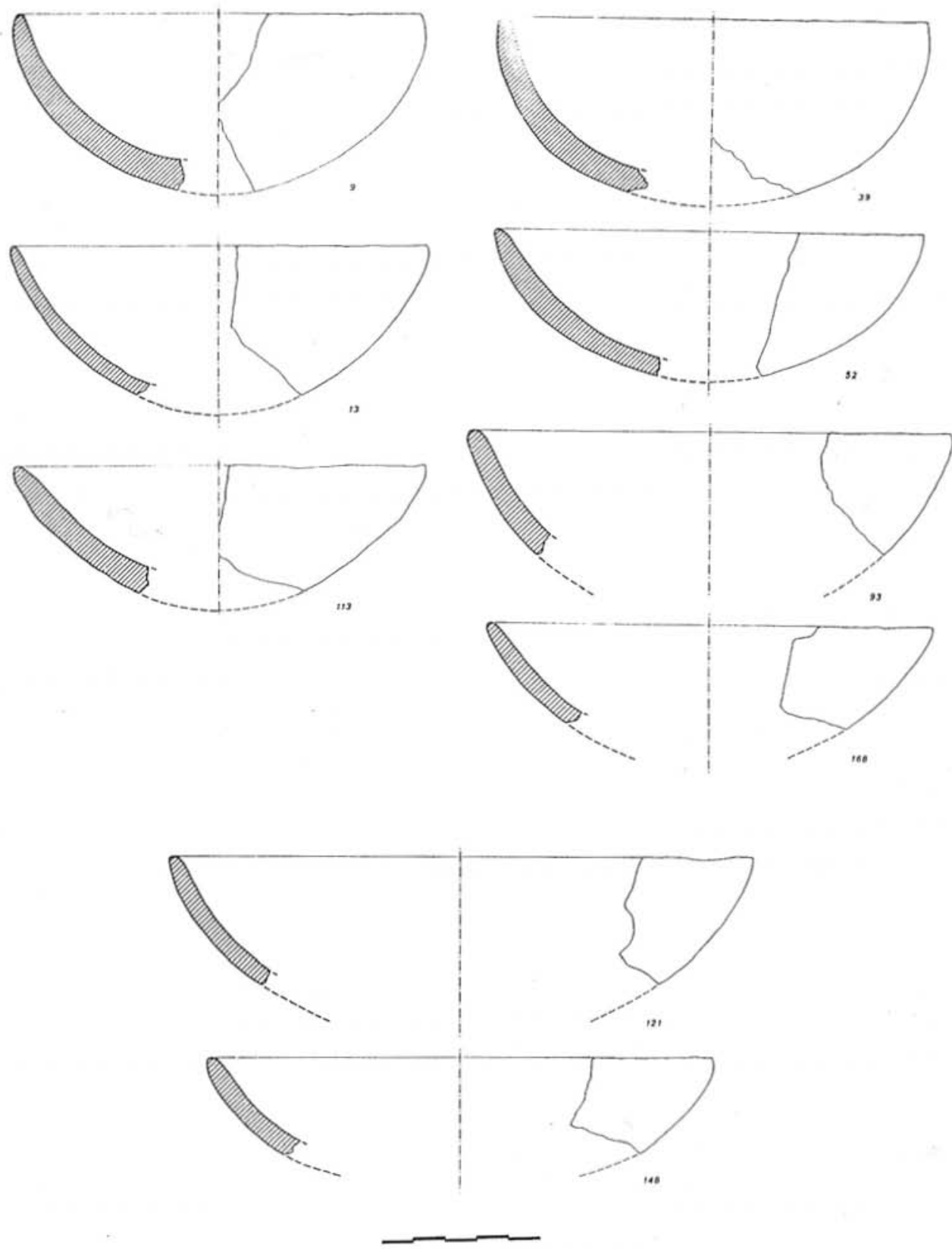

FIGURA 4

--- Grupo de investigación P.A.I. HUM 236 | http://www.arqueocordoba.com/publ/anales.htm --- 25 

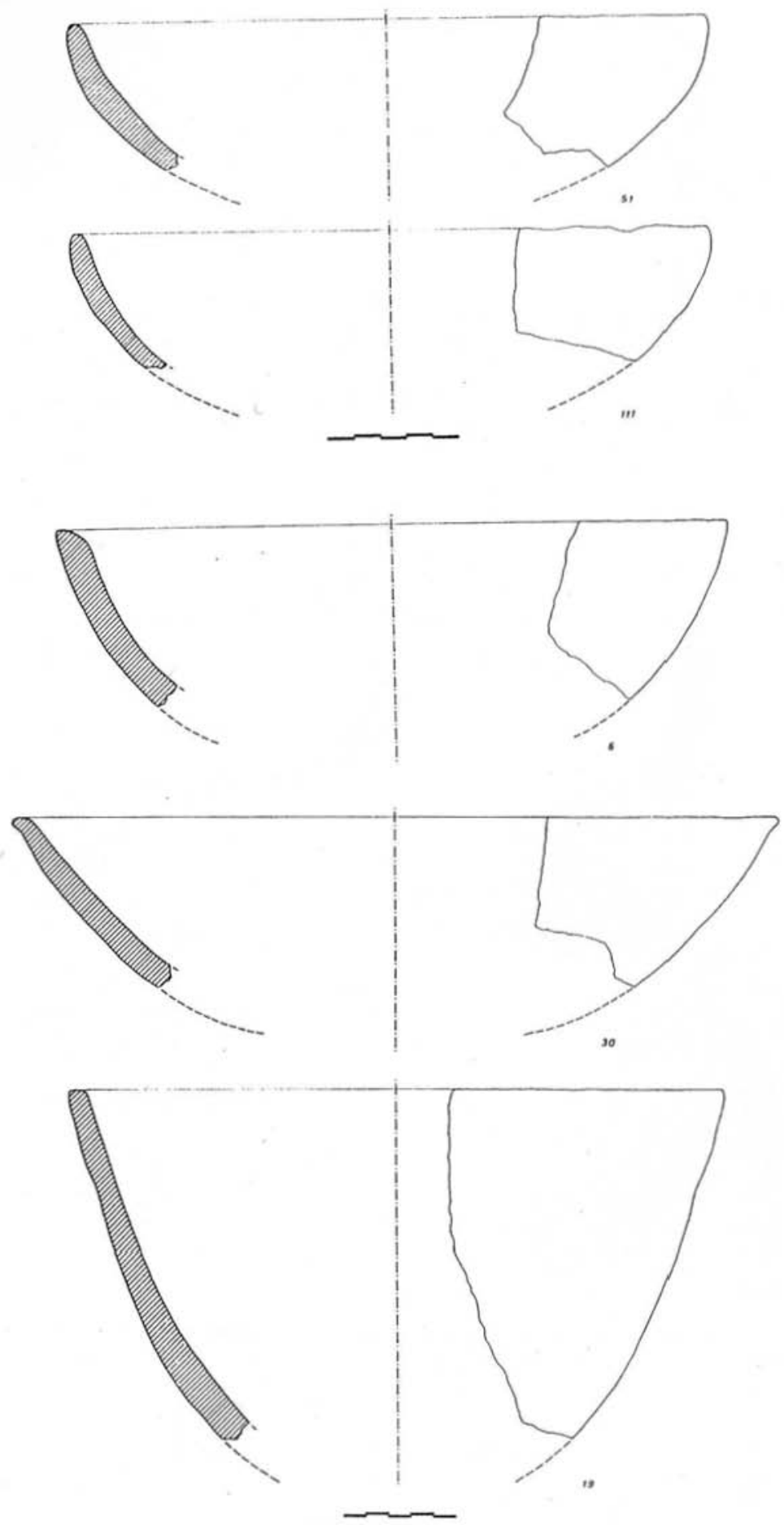

FIGURA 5 

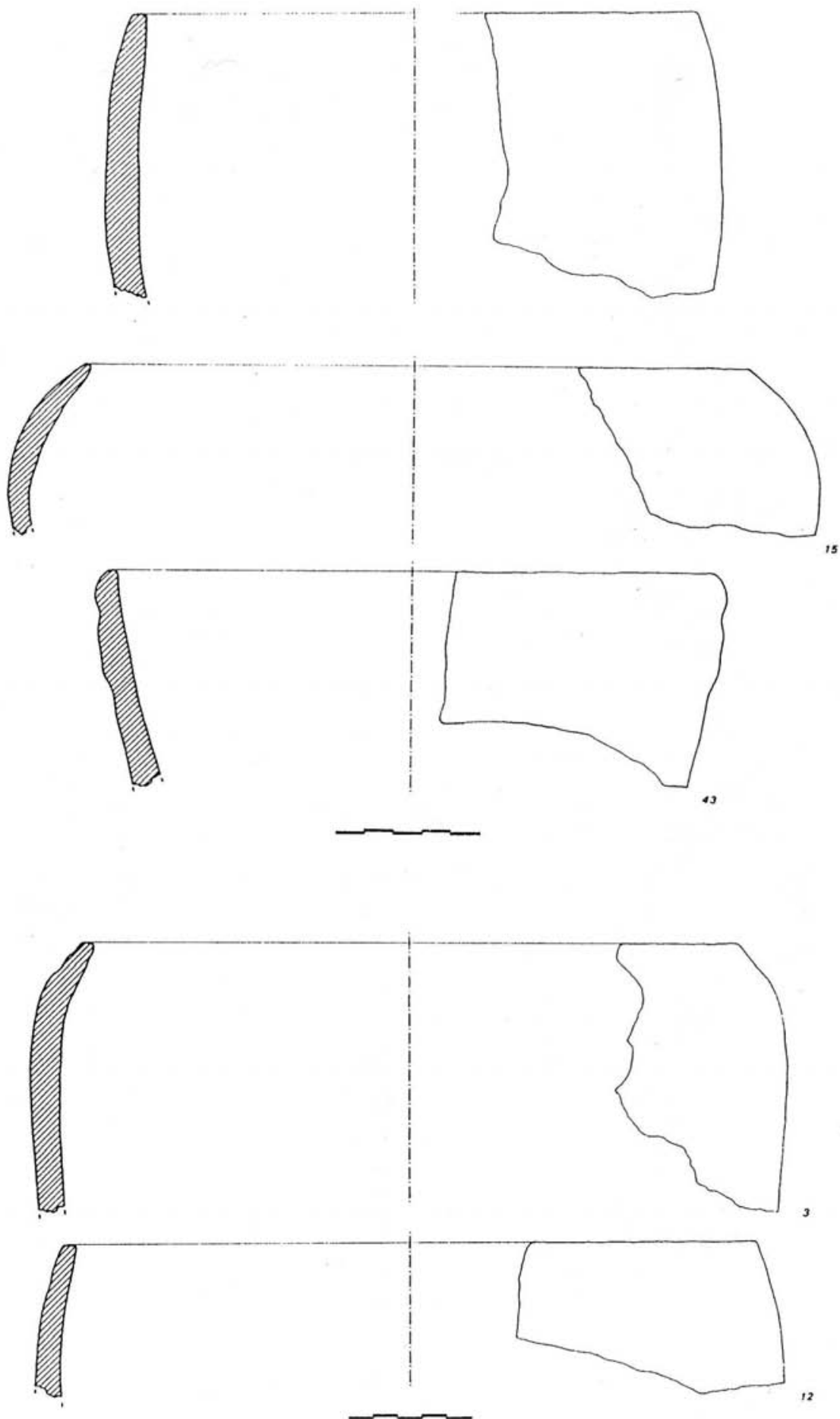

FIGURA 6

--- Grupo de investigación P.A.I. HUM 236 | http://www.arqueocordoba.com/publ/anales.htm --- 

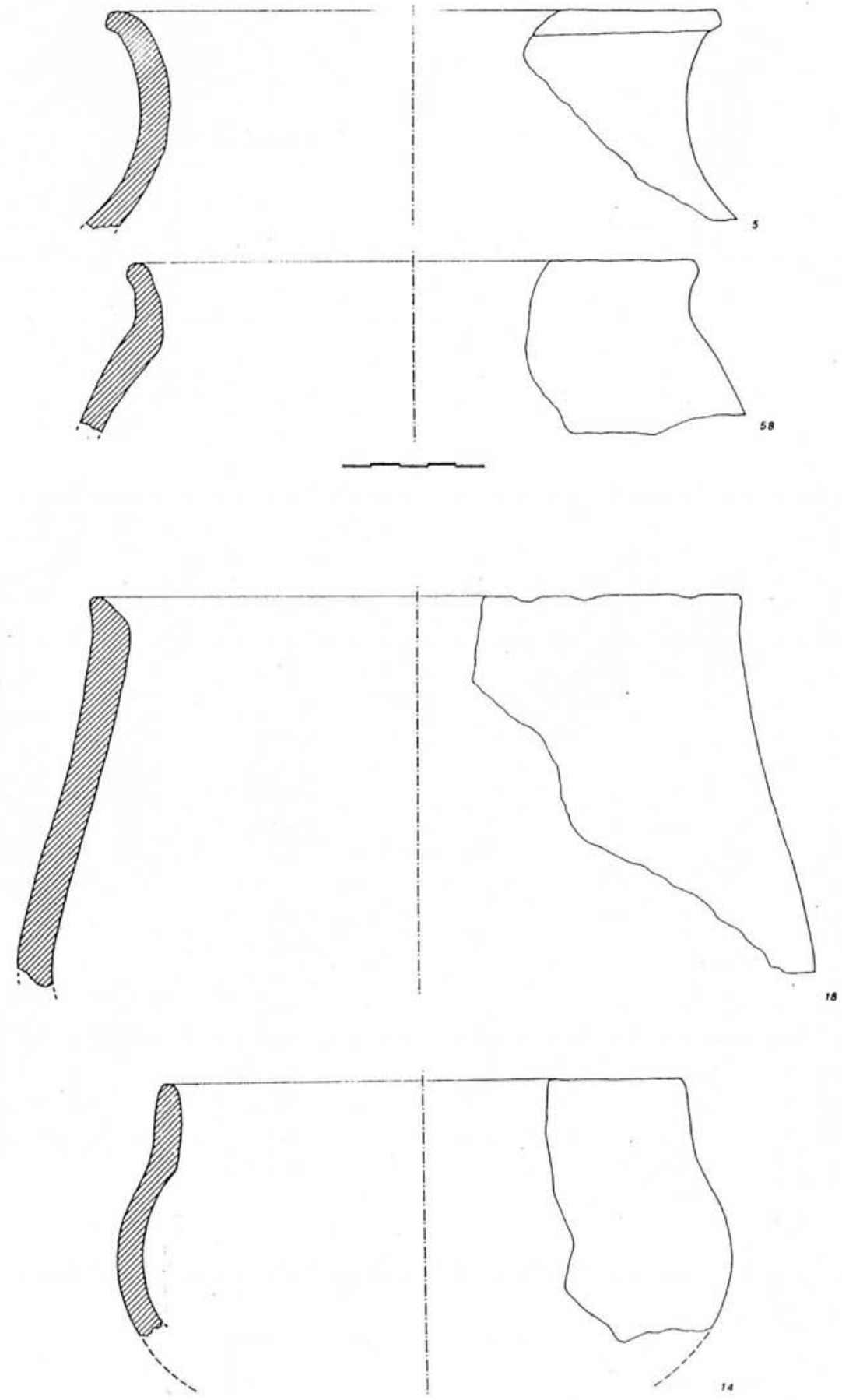

FIGURA 7

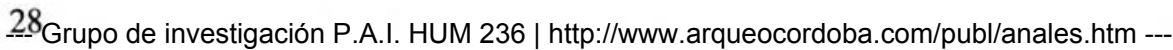



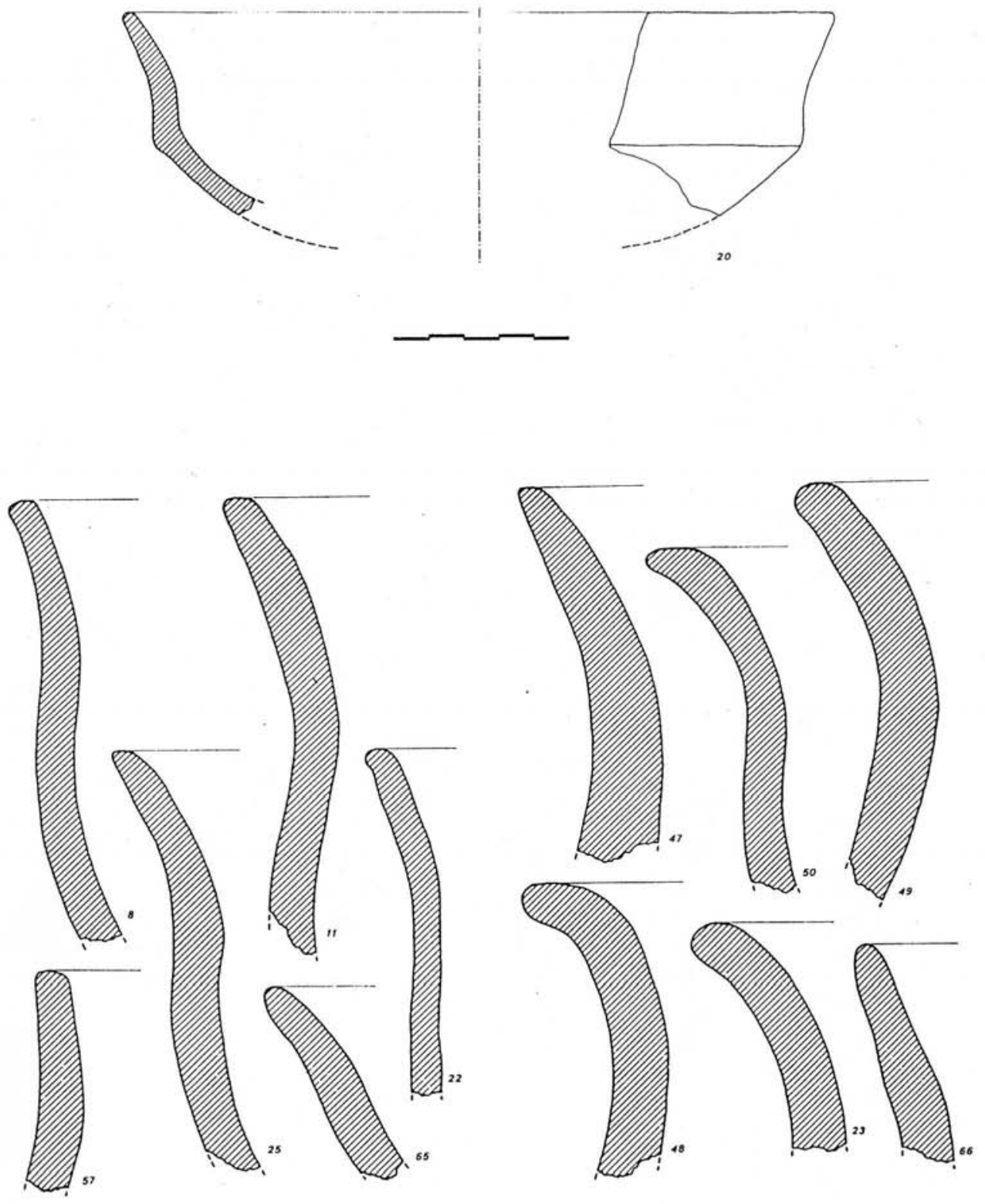

FIGURA 8

--- Grupo de investigación P.A.I. HUM 236 | http://www.arqueocordoba.com/publ/anales.htm 29 

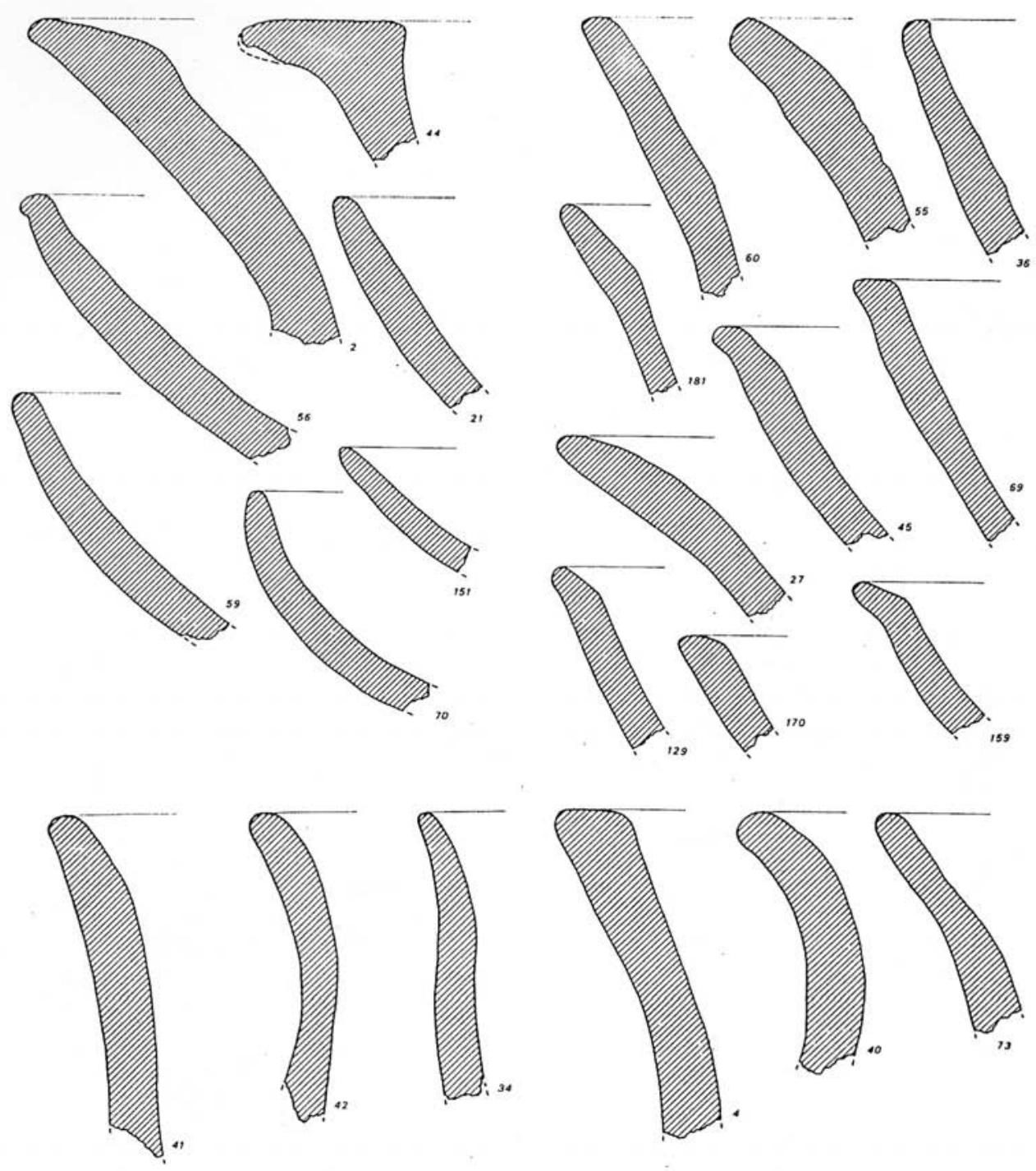

FIGURA 9 

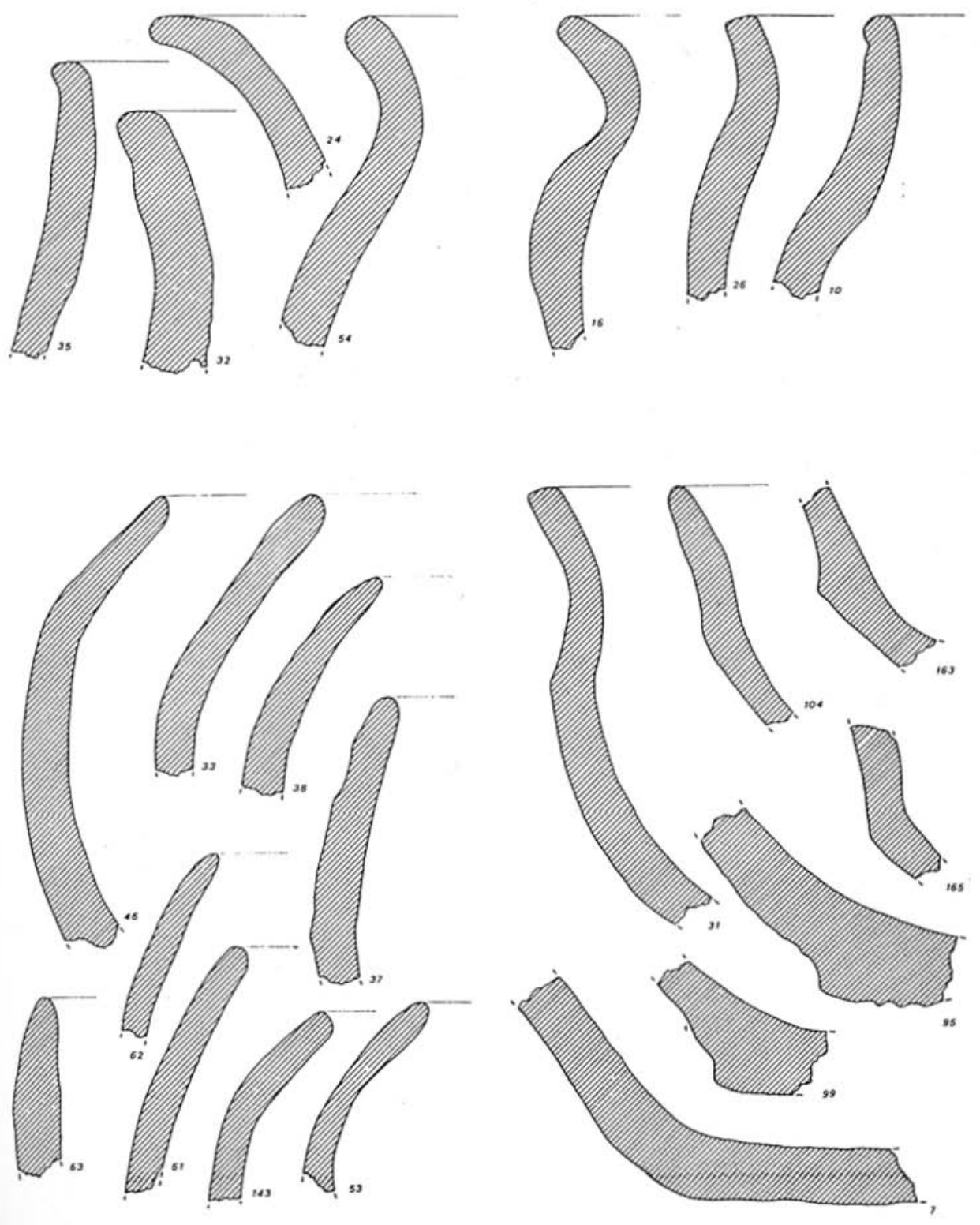

FIGURA 10 

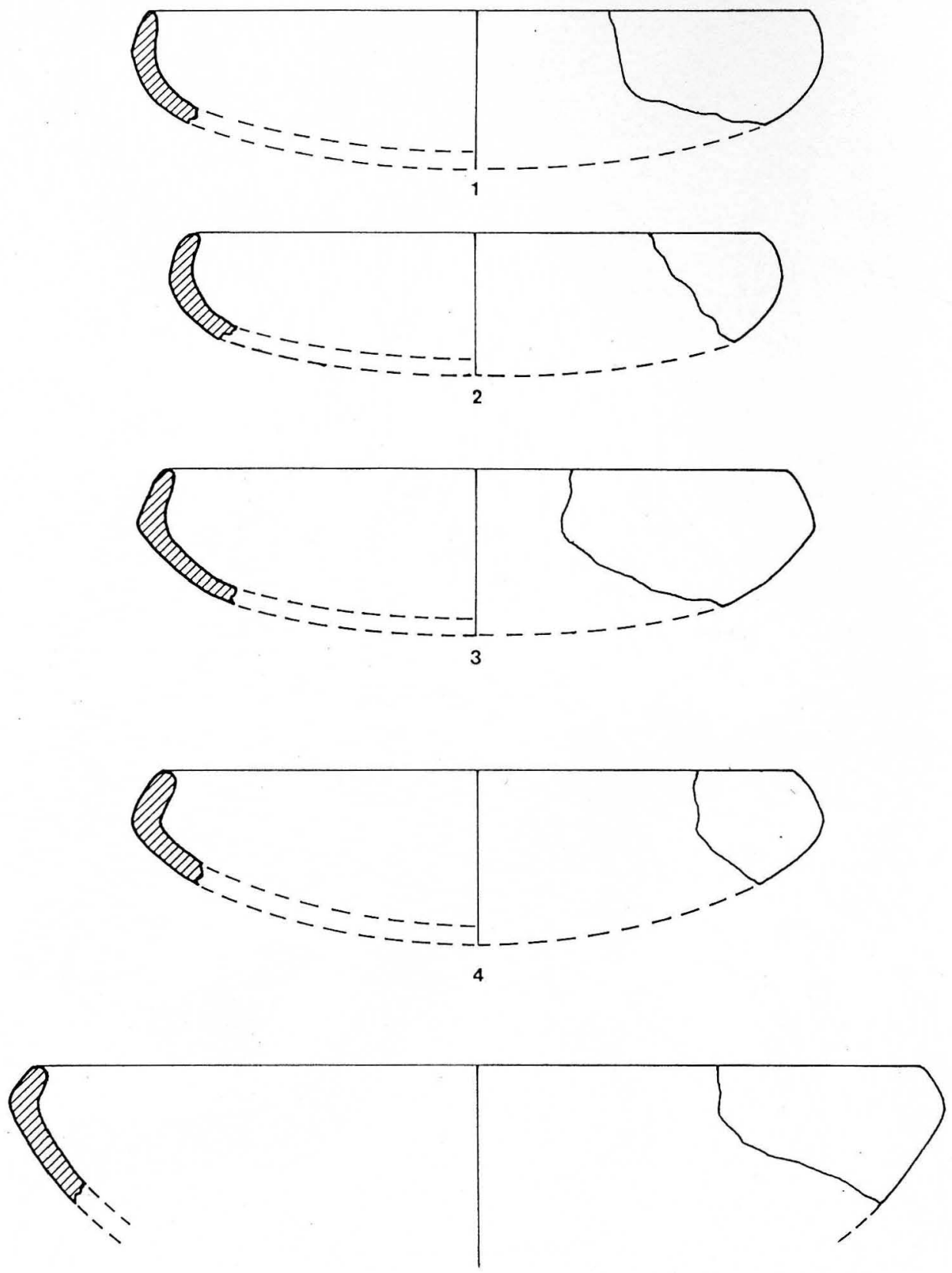

5

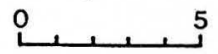

FIGURA 11 


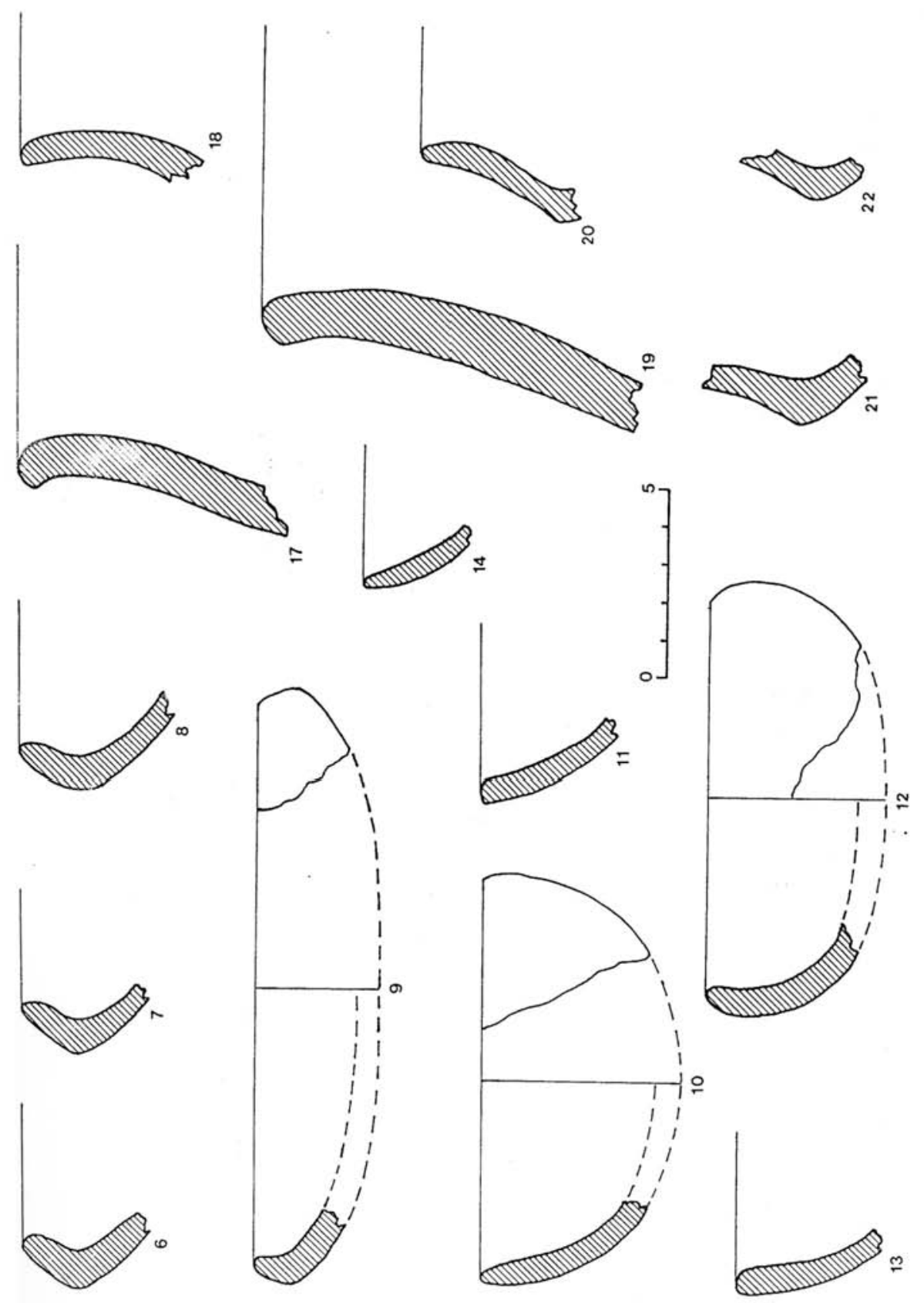

FIGURA 12 


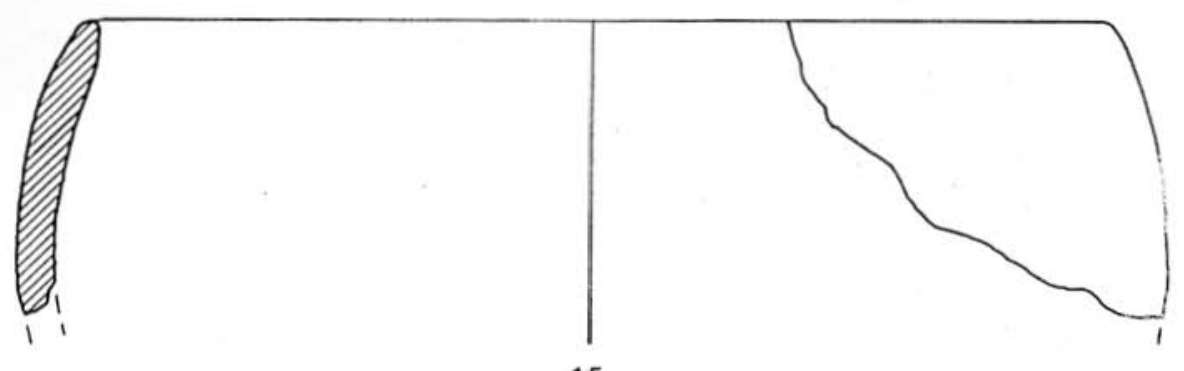

15

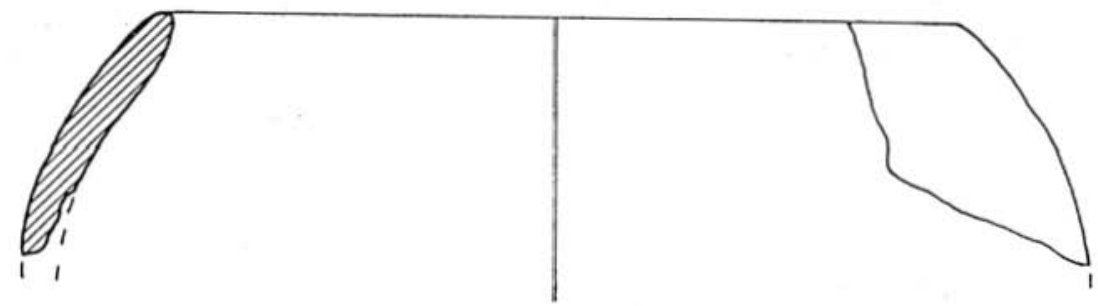

16

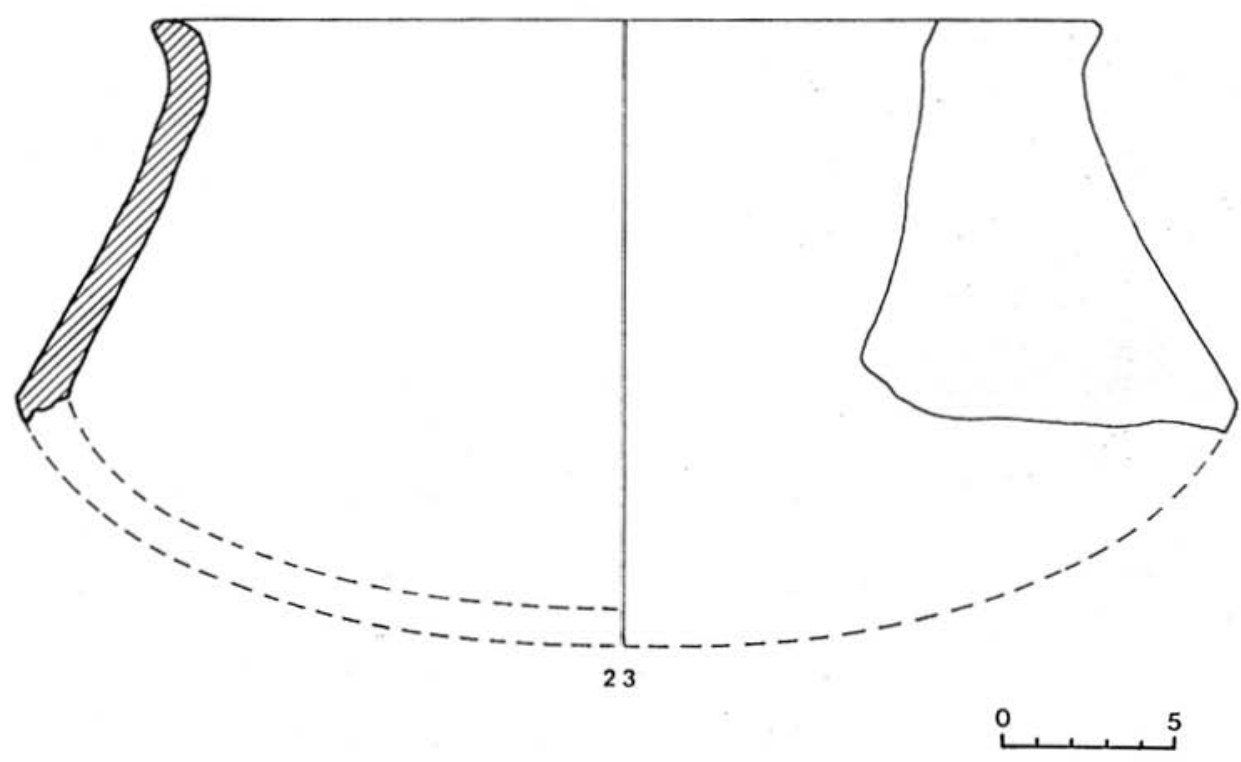

FIGURA 13

34- Grupo de investigación P.A.I. HUM 236 | http://www.arqueocordoba.com/publ/anales.htm --- 


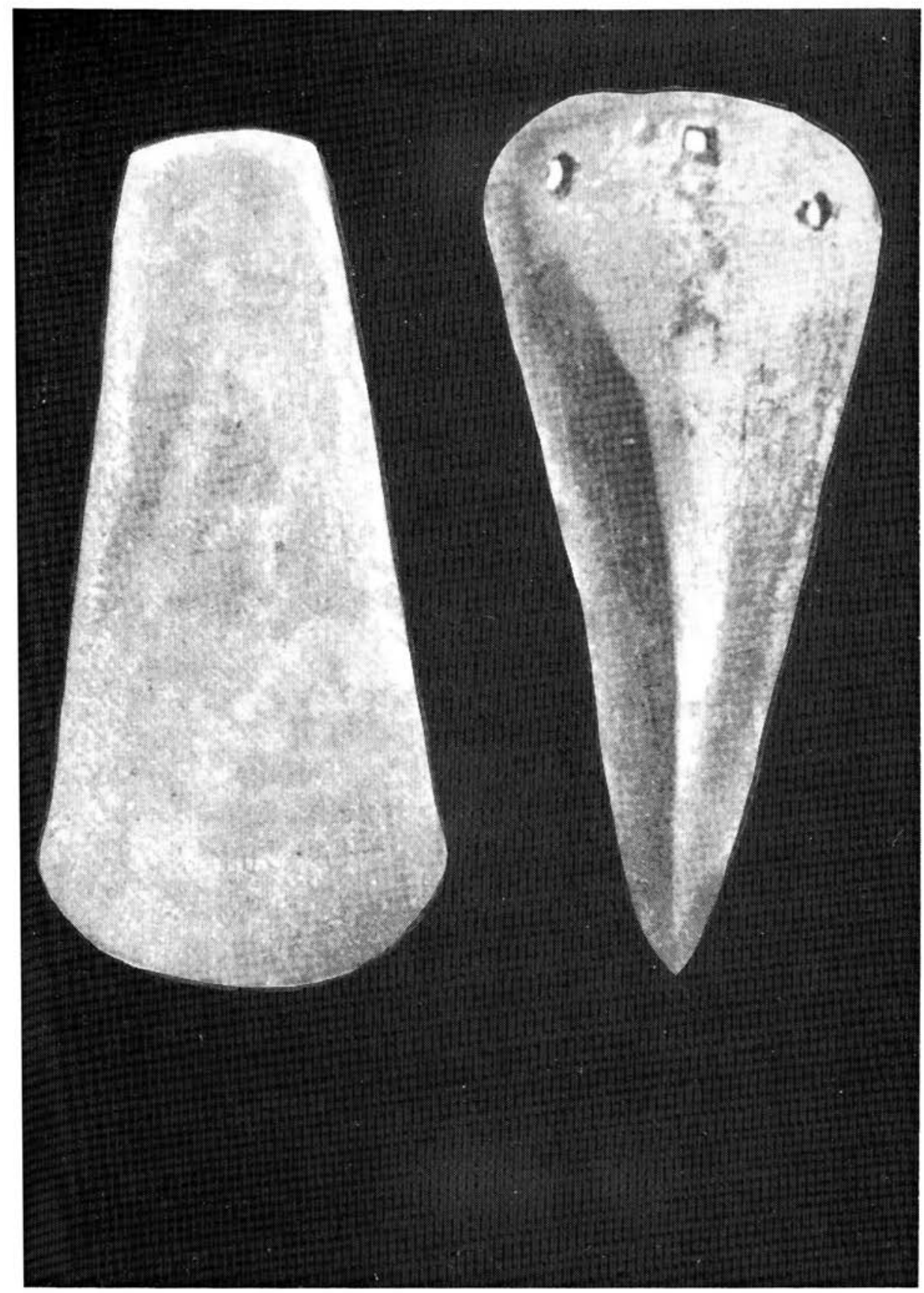

FIGURA 14 